\title{
Fraseologismo em língua de sinais e tradução: uma discussão necessária ${ }^{1}$
}

\author{
Phraseologism in Sign Language and \\ Translation: a Necessary Discussion
}

Andréa Michiles Lemos*

Instituto Federal de Educação, Ciência e Tecnologia do Ceará

Fortaleza - Ceará / Brasil

\begin{abstract}
RESUMO: O objetivo deste trabalho é investigar as estratégias de interpretação utilizadas no processo tradutório do português para a língua brasileira de sinais (Libras), em interpretações que envolvem Unidades Fraseológicas (UF's) utilizadas por políticos em seus discursos. Considerando que as línguas em questão são de modalidades diferentes, a primeira oral-auditiva e a segunda viso-espacial, levantamos as seguintes questôes: Como o intérprete de Libras faz para interpretar UF's do português para a Libras? Quais estratégias de interpretação são utilizadas pelos intérpretes de língua de sinais na interpretação de UF's? Para responder a essas questōes analisamos vídeos, com interpretaçōes para a Libras, de Sessões Plenárias da Assembleia Legislativa do Estado do Ceará. Nosso trabalho se insere no rol das pesquisas descritivas. A análise do corpus aponta para o uso, preferencialmente, de duas estratégias de interpretação das seis estratégias que classificamos.

PALAVRAS-CHAVE: Tradução, Interpretação, Estratégias, Fraseologia.
\end{abstract}

ABSTRACT:The aim of this study is to investigate the interpreting strategies used in the translation process from Portuguese to Brazilian Sign Language (Libras) in interpretations which involve phraseological units (PhU) used by State Representatives in their political speeches. Taking into account that the referent languages concerned are of different modalities - the first oral-auditory and the second visual-spatial - this study seeks to examine the following issues: How do interpreters of Brazilian Sign Language interpret PhU from Portuguese to Libras? Which interpreting strategies are used by sign language interpreters in the interpretation of PhU? To answer those questions, this work analyzed

\footnotetext{
*andmichiles@gmail.com

${ }^{1}$ Este trabalho é resultado de uma pesquisa de Mestrado em Linguística, orientada pela Profa. Dra. Rosemeire Selma Monteiro-Plantin (UFC). Pesquisadora vinculada ao Programa de Pós-Graduação da Universidade Federal do Ceará. Vice Presidente da Associação Brasileira de Fraseologia.
} 
Plenary Sessions videos of the Legislative Assembly of the State of Ceará, with interpretations in Libras and fits within the realm of descriptive research. Corpus analysis points to the preferable use of two interpreting strategies from a list of six strategies classified in this study.

KEYWORDS: Translation, Interpreting, Strategies, Phraseology.

\section{INTRODUÇÃO}

Os estudos fraseológicos, durante anos, ficaram à margem dos estudos linguísticos e, só recentemente esses estudos têm despertado maiores interesses de pesquisa. Para Gurillo (1997), a Fraseologia foi, durante muito tempo, 'terra de ninguém', na qual pesquisadores de várias escolas, movidos pelo interesse de estudar as 'combinações fixas de palavras' de uma língua, transitaram. Nas Línguas de Sinais, esses estudos ainda são muito incipientes, existem poucas pesquisas que investiguem a questão da fraseologia nessas línguas.

Neste estudo, além do interesse pessoal pelos estudos da tradução, especialmente no que se refere à interpretação que envolve línguas de modalidades de articulação diferentes, como é o caso da Língua de Sinais (gesto-visual) e da Língua Portuguesa (oral-autidiva), há também o interesse em investigar e descrever as estratégias de interpretação adotadas pelos tradutores-intérpretes ${ }^{2}$ de Línguas de Sinais e de Língua Portuguesa (doravante TILSP), nas interpretações de Unidades Fraseológicas (UFs) do Português para a Libras, nas janelinhas de Libras das Sessões Plenárias da Assembleia Legislativa do Estado do Ceará (ALEC), transmitidas pela TV Assembleia. ${ }^{3}$

A transmissão de programas televisivos com a janelinha de Libras tornou-se mais frequente após a aprovação das leis 10.098/2000 e 10.436/2002 e do Decreto 5626/2005: as leis são, respectivamente, a Lei da Acessibilidade e a Lei da Libras, como ficou conhecida. Essas conquistas garantiram ao surdo não somente o acesso à comunicação, como também ajudou na difusão da Língua de Sinais.

\footnotetext{
${ }^{2}$ Denominaremos os intérpretes de Libras de tradutores-intérpretes porque esses profissionais sempre transitam entre a tradução e a interpretação em língua de sinais. Ao contrário dos intérpretes e dos tradutores de línguas orais que, geralmente, têm seu papel e atividade profissionais bem definidos.

${ }^{3}$ A TV Assembleia do Ceará, adota a janelinha de Libras nas transmissões de alguns de seus programas desde o ano de 2007.
} 
Neste artigo, temos o objetivo de apresentar as estratégias de interpretação utilizadas pelos TILSP, na interpretação de UFs da Língua Portuguesa para a Libras, nas janelinhas de interpretação das Sessões Plenárias da ALEC.

\section{FRASEOLOGIA - conhecendo a teoria}

Podemos dizer que a Fraseologia é uma disciplina recente e que sempre esteve à margem nos estudos linguísticos. Os primeiros registros formais de estudos fraseológicos datam do século XX com Charles Bally (Précis de stylistique, 1905, e Traité de stylistique, 1909), que foi aluno e seguidor de Ferdinand de Saussure, além de fundador da linguística moderna. De acordo com Zuluaga (1980), Bally é considerado por muitos linguistas como o "pai" da Fraseologia, pois foi o primeiro que se deteve a investigar e a analisar exaustivamente os fenômenos fraseológicos. Antes de Bally, alguns pesquisadores haviam mencionado e chamado atenção para as expressões toutes faites - como eram chamadas por Saussure. Pesquisadores anteriores a Saussure como Hermann Paul (1880) e Michel Breal (1897), de acordo com Zuluaga (1980), também sinalizaram a importância de estudar essas expressōes da língua, que parecem ser uma "unidade" de significados. Para Saussure (2006, p.144), "um grande número de expressões que pertencem à língua; são as frases feitas, nas quais o uso proíbe qualquer modificação"; para Breal, ${ }^{4}$ a língua possui expressões cujos elementos linguísticos estão ligados há tanto tempo que para nós não é mais possível distinguir seus significados separadamente.

Alguns advogam que a disciplina Fraseologia surgiu a partir dos estudos fraseológicos soviéticos, também no século XX, e tem como fundador dos estudos fraseológicos o linguista soviético V. V. Vinogradov (CORPAS PASTOR, 1996). O fato é que tanto a obra de Charles Bally como os muitos estudos dos linguistas soviéticos trouxeram grandes contribuições para os estudos fraseológicos e ajudaram a firmar a Fraseologia enquanto disciplina, embora ainda nos tempos de hoje haja uma polêmica em como definir a Fraseologia: se como uma disciplina autônoma ou como uma subdisciplina da Lexicologia. Seja como for, é importante reconhecer a relevância dos estudos fraseológicos na Linguística.

4 "Comme les pièces d'un engrenage, que nous sommes si habitués à voir sadapter l'une dans l'autre que nous ne songeons pas à nous figurer séparées, le langage présente des mots que l'usage a réunis si longtemps qu'ils n'existent plus pour notre intelligence à l'etat isolé." (BREAL apud ZULUAGA, 1980, p.35). 
Em toda área do conhecimento é necessário que tenhamos um objeto de estudo definido. Desse modo, nos estudos fraseológicos temos a unidade fraseológica (UF) como elemento central à Fraseologia. Aportados nas definiçōes de alguns autores, Gurillo (1997), Zuluaga (1980), Corpas Pastor (1996) e Tagnin (2005), entendemos por Unidades Fraseológicas (UFs), as unidades léxicas formadas por duas ou mais palavras, que apresentam algum grau de fixação e algum grau de idiomaticidade. Na constituição de uma UF, o significado individual das palavras se perde parcial ou totalmente, as palavras deixam de significar individualmente e passam a constituir uma unidade 'indestrutível' de significados, na qual a coesão é absoluta, não sendo possível a decomposição dessas UFs em partes e nem a permuta de seus elementos por sinônimos.

As UFs não são identificadas apenas por uma característica, mas por um conjunto de características. Apresentamos aqui algumas das citadas por Pastor (1996) e Zuluaga (1980):

-A fixação (inalterabilidade da ordem de seus elementos, invariabilidade de alguma categoria gramatical, insubstituibilidade de seus elementos, impossibilidade de introduzir ou omitir novos elementos);

-Especialização semântica - a idiomaticidade;

-A frequência de uso - a institucionalização;

-A gradação.

Esses elementos da língua sempre foram estudados pelos pesquisadores e linguistas e receberam diferentes nomenclaturas, tais como: expressöes formuláicas, idiomatismos, lexias complexas, expressöes pluriverbais, expressöes cristalizadas, expressóes fixas, entre outras. No entanto, a maioria dos linguistas adota e nós também adotamos o termo Unidade Fraseológica, pois consideramos ser a terminologia mais ampla e que abrange melhor a todos esses fenômenos.

Em relação aos estudos linguísticos - com foco na fraseologia - das línguas de sinais, percebemos que ainda são poucas as investigaçôes com o objetivo de explorar esse fenômeno da língua, e mesmo as pesquisas existentes não focam exclusivamente as UFs nas línguas de sinais (LS). Precisaríamos de mais estudos para afirmar de que maneira as UFs se realizam nessas línguas, tendo em vista que as línguas de sinais têm uma modalidade de realização visual e espacial diferente das línguas orais-auditivas. Por essa 
razão, entendemos que a realização das UFs possa acontecer de maneira diferenciada.

Faria (2003, p.78) afirma que "aparentemente, há indícios de que as combinações fixas na LSB ${ }^{5}$ não são muitas." Por outro lado, em seu estudo, a pesquisadora identificou muitos itens lexicais em Libras que expressam "unidades complexas de pensamento". Ao procurar fraseologismos, a autora acabou encontrando muitos itens lexicais cujas traduções, por curiosidade, muitas vezes, resultam em fraseologismos em língua portuguesa. Stumpf acredita que a tendência das línguas de sinais é "condensar" vários sinais que poderiam ser utilizados para explicar um determinado conceito em apenas um sinal. Essa pesquisadora afirma que "conceitos que nós surdos passamos a usar seguidamente em língua de sinais brasileira e precisam de vários sinais para explicar acabam por dar origem a um novo sinal". (STUMPF, 2003, p.67)

Assim como Faria (2003), acreditamos que essa particularidade de 'condensação' ou de síntese dos sinais seja favorecida por causa da modalidade gesto-visual de realização da língua. A estrutura organizacional dos sinais no espaço permite a realização sequencial ${ }^{6}$ e, ao mesmo tempo, simultânea dos signos, todos os parâmetros (fonemas) se realizam no mesmo instante, podendo o falante fazer uso de sinais complexos, envolvendo simultaneamente diversas partes do corpo do sinalizador.

A modalidade de realização da língua de sinais pode favorecer a "cristalização de ideias em unidades lexicais com um único significante, porém, com significado amplo e complexo” (FARIA, 2003, p.82). Dessa forma, os fraseologismos em Língua Portuguesa ao serem traduzidos para a Língua de Sinais teriam a tendência a serem "resumidos" a um único item lexical. Mas, essas afirmações ficam ainda no campo das hipóteses, pois, como já mencionamos anteriormente, ainda temos poucas investigaçôes nesse campo de estudo para que possamos chegar a uma assertiva conclusiva.

\footnotetext{
${ }^{5}$ LSB é a nomenclatura de Língua de Sinais Brasileira. Essa nomenclatura segue uma "convenção internacional de que as Línguas de Sinais sejam identificadas por meio de três letras" (QUADROS, 2000). Optamos pela nomenclatura Língua Brasileira de Sinais (Libras), por ser esse o nome mais conhecido e o que acabou sendo reconhecido por lei. A escolha de uso de uma nomenclatura ou de outra é mais uma posição políticoideológica, adotada por parte da comunidade surda e por parte de pesquisadores da área. ${ }^{6}$ Alguns estudos tratam da sequencialidade na formação fonológica dos sinais, como, por exemplo, os estudos sobre "movimentos e suspensōes" (hold x movement - na American Sign Language) de Liddell e Johnson (2000).
} 
Entendemos que mesmo diante da possibilidade da tendência à "condensação" dos sinais, não bastaria ao tradutor-intérprete fazer o uso de um item lexical em LS para expressar o conteúdo de uma UF em Língua Portuguesa (LP). Na atividade de interpretação/tradução de fraseologismos, assim como em qualquer outro ato interpretativo/tradutório, os processos de identificação, compreensão e passagem de uma língua a outra

[...] não correspondem a mecanismos lineares e implicam uma reflexão profunda sobre o acto de tradução da fraseologia, na medida em que estas estruturas não obedecem, aparentemente, a critérios objectivos de selecção e implicam uma multiplicidade de saberes linguísticos e extralinguísticos e de escolhas por parte do tradutor. (JORGE, 2002, p.119)

A tradução/interpretação envolve muito mais do que uma simples troca de itens lexicais e gramaticais entre línguas. Por essa razão, o tradutor/ intérprete não deve realizar uma simples "transposição" linguística, mas, de acordo com Xatara, Riva e Rios (2001), é necessário, como primeiro passo para a tradução de uma UF, identificá-la na língua como uma unidade, muitas vezes como um idiomatismo, e não como uma expressão similar: "Pensar sobre qualquer tradução implica primeiramente conhecer o objeto a ser traduzido, tanto com relação a seu papel no sistema linguístico quanto com relação a seu significado." (XATARA; RIVA; RIOS, 2001, p.185).

E se de fato for tendência nas LS essa "condensação" de significados? Pressupóe-se que o TILSP deva ter conhecimento e sensibilidade para reconhecer essas "expressões" nas Línguas de Sinais. Esse conhecimento deve ser desenvolvido e aprofundado na comunidade surda ${ }^{7}$ e no contato direto com a Língua de Sinais. A interpretação/tradução de UFs, em qualquer língua e também "em língua de sinais, coloca diversas questôes de carácter linguístico e cultural que o intérprete deve conhecer e aplicar para que tenha um bom desempenho". (ALMEIDA, 2010, p.1).

\section{ESTRATÉGIAS DE TRADUÇÃO/INTERPRETAÇÃO}

Ao falarmos de interpretação nos estudos da tradução, remetemo-nos a uma área específica da tradução, mais precisamente à vertente denominada de estudos da interpretação (Interpreting Studies), estudos que remontam à

\footnotetext{
${ }^{7}$ Para saber mais sobre comunidade surda consultar Strobel (2008).
} 
década de 1950 (GILE, 1991). No discurso especializado ao qual o termo "interpretação" está inserido, este faz menção ao ato de interpretar línguas. Em nossa pesquisa, o tipo de interpretação é a "interpretação na mídia", nomenclatura empregada por Pagura (2003), na modalidade simultânea. Escolhemos essa nomenclatura, pois acreditamos que, dentre as existentes, é a que mais se ajusta aos nossos interesses. Nos vídeos analisados, o intérprete de Libras interpreta a fala do político ao mesmo tempo em que o discurso é proferido, sem tempo para revisões.

Algumas crenças relacionadas à tarefa de interpretar/traduzir - tais como: a interpretação/tradução é uma arte reservada a uns poucos que podem exercê-la graças a um dom especial; a interpretação/tradução é uma atividade prática que requer apenas um conhecimento da língua e um bom dicionário; o intérprete/tradutor deve ser falante bilíngue ou ter morado num país onde se fala a língua estrangeira do par linguístico com que trabalha; todo intérprete/tradutor é um traidor, entre outras - são crenças não somente inadequadas, como também podem interferir negativamente no processo de aprendizagem e desenvolvimento dos profissionais da tradução. Muitos acreditam que traduzir/interpretar é apenas fazer transferência de códigos entre línguas, mas na verdade, é uma atividade desafiadora, que envolve não somente conhecimento proficiente das línguas e culturas envolvidas, como também o uso de estratégias que possibilitem uma melhor e eficiente tradução/interpretação. Denominamos de estratégias de tradução/ interpretação as "alternativas" e "escolhas" de tradução/interpretação das quais o tradutor/intérprete "lança mão" durante a realização de uma atividade tradutória. É preciso lembrar que a atividade de tradução/interpretação requer uma formação e uma qualificação que propicia ao profissional as habilidades necessárias para tal atividade.

Ancorados na perspectiva dos estudos descritivos da tradução, fomos buscar uma sustentação teórica para fundamentar a nossa discussão. O objetivo dos estudos descritivos é entender e descrever o processo de tradução/interpretação, não submetendo-o a julgamento. Pensando por esse viés, não existe uma interpretação/tradução mais correta ou menos correta, o que existe são escolhas que o intérprete/tradutor faz durante um processo tradutório. Além da perspectiva dos estudos descritivos, buscamos construir uma análise do processo tradutório baseando-nos em uma proposta de tradução ligada à perspectiva da Análise do Discurso (AD). Embora, nossos estudos na $\mathrm{AD}$ sejam ainda incipientes, entendemos o processo tradutório 
como um processo discursivo que é gerador de um produto: o texto traduzido. Ou seja, entendemos que num processo de tradução, o tradutor/ intérprete é um "sujeito enunciador interpelado por uma Formação Discursiva que, por sua vez, é aberta ao interdiscurso" (MITTMANN, 2003, p.103), não sendo esse tradutor/intérprete nem o "instrumento neutro de transporte" do discurso/texto do autor, nem o dono do discurso/texto enunciado por ele em uma tradução.

Toury (1995), autor da teoria dos estudos descritivos da tradução, defende que a tradução é um tipo de atividade que envolve, inevitavelmente, pelo menos duas línguas e duas culturas diferentes, ou seja, pelo menos dois conjuntos de normas diferentes estariam em contato. As normas seriam as regularidades observadas no comportamento tradutório.

Novais (2002) e Hortêncio (2005), aportados nos estudos descritivos de Toury (1995), identificaram e classificaram tipos de estratégias para o processo tradutório. Suas investigações acerca das estratégias de tradução tiveram foco na interpretação oral ${ }^{8}$ simultânea. $O$ primeiro pesquisador investigou as estratégias de interpretação utilizadas por profissionais intérpretes (de língua oral) de tribunal e propôs sete estratégias de interpretação: simplificação, omissão, síntese, discurso indireto, ratificação, padronização e explicitação. A segunda pesquisadora analisou as estratégias de interpretação classificadas por Novais (2002), e, além de verificar a aplicabilidade dessas estratégias ao processo tradutório em interpretaçôes simultâneas do Português para a Língua Brasileira de Sinais, no âmbito das Testemunhas de Jeová, ela também classificou outras estratégias de interpretação que parecem ser peculiares a essa modalidade de interpretação. Em seu estudo, Hortêncio (2005), além das sete estratégias apontadas por Novais (2002), identifica outras três estratégias que são utilizadas pelos TILSP, a saber: a repetição, o uso de recursos visuais e o uso de perguntas retóricas para destacar informações importantes, para prender a atenção e para estimular o raciocínio.

Neste estudo analisamos se as estratégias citadas por Novais (2002) e Hortêncio (2005) são aplicáveis ao processo tradutório de UFs do Português

\footnotetext{
${ }^{8}$ Por uma questão de padronização, utilizamos o termo "interpretação oral" para todas as interpretações realizadas entre línguas, sejam interpretaçôes entre línguas orais ou entre línguas de sinais ou, ainda, entre uma língua oral e uma língua de sinais. Entendemos que o termo 'oral', neste caso, deve ser entendido como 'ato da fala', seja ela uma fala oral ou uma fala sinalizada.
} 
para a Libras, no contexto de discursos de políticos e verificamos que outras estratégias aparecem nesse contexto de interpretação.

Antes de entrarmos na análise das estratégias, gostaríamos de pontuar que compreendemos e classificamos a estratégia uso de recurso visual, apresentada por Hortêncio (2005), de maneira diferenciada. A pesquisadora classificou essa estratégia pensando no uso do alfabeto manual e nos recursos visuais físicos (tais como o uso de vídeo, de imagens) utilizados pelos tradutores-intérpretes de Libras para auxiliá-los na interpretação. Em nosso entendimento, a nomenclatura dada a essa estratégia é muito geral, muitos elementos nas Línguas de Sinais podem ser denominadas de recurso visual, não existindo nessa classificação uma clareza de definição. Além de não concordarmos com a autora quanto à nomenclatura dada à estratégia, não concordamos também com a sua descrição, pois, para nós, o uso de recursos visuais físicos, tais como imagens, projetores, vídeo, entre outros, classificados por Hortêncio (2005), pode até ser concebido como estratégia de busca de subsídios externos, tal como as classificadas por Alves, Magalhães e Pagano (2006), mas entendemos essa "estratégia" muito mais como recursos metodológicos que podem auxiliar uma interpretação, do que como uma estratégia de interpretação/tradução propriamente dita.

Preferimos reclassificar essa "estratégia", apontada por Hortêncio (2005), e a recategorizarmos em duas outras estratégias: a primeira nós chamamos de uso de datilologia - entendemos que o uso desse recurso da datilologia, ou seja, do alfabeto manual, além de ser um empréstimo linguístico da Língua Portuguesa para a Língua de Sinais, pode ser considerado uma estratégia de tradução/interpretação que a própria Língua de Sinais oferece; a segunda nós denominamos de paráfrase descritiva nessa estratégia o TILSP pode explorar o espaço de sinalização, assim como o uso de recursos manuais e/ou de classificadores (os classificadores são recursos visuais importantíssimos nas línguas de sinais), como estratégias interpretativas que melhor o apoiarão em uma interpretação. Dessa forma, diante de nosso entendimento, reclassificamos a estratégia uso de recurso visual, nomeada por Hortêncio (2005), nas estratégias uso de datilologia e paráfrase descritiva, como veremos adiante.

\section{METODOLOGIA E ANÁLISE DOS DADOS}

O procedimento inicial para o nosso estudo consistiu em coletar vídeos gravados, em DVD, de sessões plenárias da Assembleia Legislativa 
do Estado do Ceará (ALEC). Em um primeiro momento, assistimos aos vídeos gravados e fizemos uma seleção das falas de parlamentares em que mais se evidenciavam o uso de unidades fraseológicas; buscando sempre identificar que tipos de UFs apareciam - nesse momento a língua em foco era a Língua Portuguesa -, fizemos uma transcrição dos trechos em que essas expressōes apareciam. Em seguida, assistimos aos vídeos para fazer a marcação da interpretação do TILSP. Para essa marcação utilizamos as chamadas glosas - nesse momento a língua em foco era a Língua de Sinais. Posteriormente, assistimos novamente aos vídeos, agora com o objetivo de fazer o levantamento e o registro das estratégias de interpretação utilizadas pelos TILSP, observando o processo de tradução entre a Língua Portuguesa e a Libras. Para finalizar o processo de análise, realizamos uma entrevista semiestruturada com os TILSP, a fim de conhecer melhor os sujeitos de pesquisa e de trazer à tona a percepção e o conhecimento deles acerca do processo tradutório e das estratégias que utilizam nas interpretaçôes. Neste artigo, discutiremos apenas alguns aspectos dessa entrevista.

Para realizarmos os procedimentos acima, utilizamos um software chamado ELAN (Eudico Linguistic Annotador), desenvolvido na Holanda pelo Instituto de Psicolinguística Max Planck. Nas palavras de Quadros e Pizzio, o ELAN

é uma ferramenta de anotação que permite que você possa criar, editar, visualizar e procurar anotações através de dados de vídeo e áudio. Foi desenvolvido [...] com o objetivo de produzir uma base tecnológica para a anotação e a exploração de gravações multimídia. ELAN foi projetado especificamente para a análise de línguas, da língua de sinais e de gestos, mas pode ser usado por todos que trabalham com corpora de mídias, isto é, com dados de vídeo e/ou áudio, para finalidades de anotação, de análise e de documentação destes (QUADROS E PIZZIO, 2009, p.22).

O ELAN é um software livre e pode ser baixado na internet, o que nos permitiu acessá-lo facilmente. Esse programa favorece a anotação de vídeos porque nos permite, em uma mesma tela, ouvir e visualizar o vídeo, além de dispor de linhas (as chamadas trilhas) para a anotação do pesquisador. As trilhas são criadas e denominadas de acordo com os objetivos da pesquisa e do pesquisador. Ilustramos abaixo o programa em uso com algumas trilhas criadas por nós:

\footnotetext{
9 Para realizar a transcrição da Libras, nós utilizamos o "sistema de notações em palavras" caracterizado por Felipe (1997).
} 


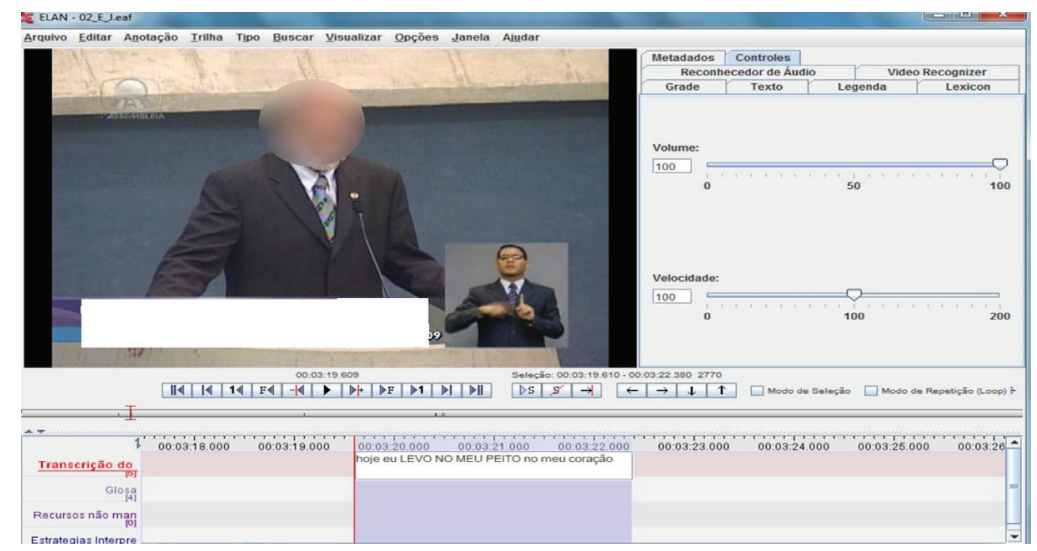

FIGURA 1: Captura do vídeo selecionado para a pesquisa.

Nosso universo consiste de gênero político na linguagem televisiva, mais especificamente das janelas de interpretação de Libras utilizadas em programas de televisão. Como corpus para a investigação, utilizamos as gravaçōes de sessōes plenárias, entre o período de fevereiro de 2008 a dezembro de 2010. O critério de seleção das sessões gravadas para compor o nosso corpus foi escolher duas sessões de cada TILSP e para a análise selecionamos somente as interpretaçôes feitas durante o ' $1{ }^{\circ}$ Expediente ${ }^{\text {'10 }} \mathrm{da}$ sessão plenária. Participaram como sujeitos desse estudo, seis profissionais tradutores-intérpretes de Libras, ligados à Associação dos Profissionais Tradutores e Intérpretes de Libras do Ceará (Apilce).

No corpus analisado encontramos e classificamos algumas UFs, que, seguindo a terminologia de Tagnin (2005), são: colocações, citaçôes, expressões idiomáticas (EI) e binômio. Abaixo organizamos em pequena amostra, juntamente com as glosas da interpretação em Libras, das expressões encontradas:

\footnotetext{
${ }^{10}$ A Sessão Plenária é sistematizada da seguinte maneira: ' 10 Expediente' - organizado em seis tempos de 15 minutos para cada parlamentar; Ordem do Dia' - momento de votação de matérias e projetos do governo com tempo indeterminado; 'Pela Ordem' - momento em que cada parlamentar tem até 3 minutos para fazer uso da palavra; '20 Expediente' - também organizado em seis tempos de 15 minutos; 'Tempo de Liderança' - tempo destinado às lideranças de partidos e/ou do governo; cada líder tem o direito de fazer uso da palavra por 10 minutos; e as 'Explicaçôes Pessoais' - momento em que cada parlamentar pode utilizar até 5 minutos para tratar de assuntos diversos.
} 


\section{QUADRO DAS UNIDADES FRASEOLÓGICAS}

\begin{tabular}{|c|c|}
\hline Transcrição da LP (discurso do político) & Glosa em Libras da interpretação \\
\hline \multicolumn{2}{|l|}{ Expressões idiomáticas } \\
\hline $\begin{array}{l}\text { eleição de prefeito para o PSDB pode TIRAR } \\
\text { O CAVALINHO DA CHUVA deputado que } \\
\text { num vai não }\end{array}$ & $\begin{array}{l}\text { CONSEGUIR VOTO }<\text { neg }>\text { DESCULPE }<\text { exp.f } \\
\text {.neg.. }>\text { NÄO }\end{array}$ \\
\hline querer TAPAR O SOL COM UMA PENEIRA & $\begin{array}{l}\text { PARECE+ SOL(md) CL: } 5 \text { PARAR(me) <exp. f. neg }> \\
\text { CL: } 5 \text { ULTRAPASSAR(md) }\end{array}$ \\
\hline \multicolumn{2}{|l|}{ Colocações } \\
\hline $\begin{array}{l}\text { isso é consequência do AQUECIMENTO } \\
\text { GLOBAL }\end{array}$ & $\begin{array}{l}\text { PORQUE <.....> O-QUE+ É POR-CAUSA MUNDO } \\
\text { DENTRO PARECER CLIMA QUENTE AUMENTAR }\end{array}$ \\
\hline PROBLEMA GRAVÍSSIMO & PROBLEMA+ SÉRIO \\
\hline GRAVE PROBLEMA que estamos vivenciando & PROBLEMA+ <exp. f ...int..> TER AGORA \\
\hline hoje certamente é DIA DE LUTO para & $\begin{array}{l}\text { HOJE É NÓS-todos TRISTE }(\mathrm{md})(\mathrm{me}) \text { L-U-T-O } \\
\text { IGUAL PRETO NÓS LEMBRAR }\end{array}$ \\
\hline \multirow{12}{*}{ TOQUE DE RECOLHER } & HORA 12 PEGAR+ \\
\hline & CL: 5(me) CL: Ä(md) TOCAR-CAMPAINHA PEGAR+ \\
\hline & PEGAR+ JUNTAR-GRUPO \\
\hline & PEGAR+ JUNTAR-GRUPO LEVAR \\
\hline & POLÍCIA FAVELA MANDAR \\
\hline & IGUAL (me) muitas-pessoas IR PRESO CASA \\
\hline & IGUAL (md) muitas-pessoas IR \\
\hline & CARRO CL: B CARONA-LEVAR CL: " 5 \\
\hline & $\begin{array}{l}\text { HORA CARRO CL: B JOGAR-DENTRO CARONA- } \\
\text { LEVAR CL: }{ }^{5} 5\end{array}$ \\
\hline & <omissão> \\
\hline & $\begin{array}{l}\text { HORA POLÍCIA CARRO CL: B JOGAR-DENTRO } \\
\text { CARONA-LEVAR CL: } " 5\end{array}$ \\
\hline & $\begin{array}{l}\text { HORA POLÍCIA VIGIAR CARRO CL: B JOGAR- } \\
\text { DENTRO CARONA-LEVAR CL: }{ }^{5}\end{array}$ \\
\hline \multicolumn{2}{|l|}{ Citações } \\
\hline EM VERDADE EM VERDADE VOS DIGO & AGORA VERDADE AVISO \\
\hline $\begin{array}{l}\text { MEU DEUS, MEU DEUS, POR QUE ME } \\
\text { ABANDONASTES? }\end{array}$ & ORARDEUS PORQUEME-ABANDONAR<.....> \\
\hline \multicolumn{2}{|l|}{ Binômio } \\
\hline DANÇOU E BAILOU & $<$ omissão $>$ \\
\hline TRANSITAMOS E ANDAMOS & $\begin{array}{l}\text { PESSOA CL: G IR-VIR <pausa> PESSOA CL: V } \\
{ }_{k d} \text { ANDAR }_{k e}\end{array}$ \\
\hline
\end{tabular}

Fonte: LEMOS, 2012. 
Constatamos, em nosso corpus, um maior número de UFs que se enquadram, de acordo com a classificação de Tagnin (2005), no grupo das colocações.

A partir dos dados encontrados, fizemos uma análise para identificar a(s) estratégia(s) que os TILSP utilizaram para interpretar a informação dada. Nesse processo, encontramos e classificamos seis estratégias principais, assim denominadas: simplificação, explicitação, tradução literal, paráfrase (explicativa e descritiva), equivalência, apagamento ou omissão. Fundamentamos e encontramos essas estratégias de tradução/interpretação em Barbosa (2004); Xatara, Riva e Rios (2001); Novais (2002) e Hortêncio (2005).

Identificamos, em nosso estudo, outra estratégia de interpretação das UFs utilizada pelos TILSP, mas não a classificamos dentro do grupo das estratégias principais, pois o seu uso sempre apareceu de maneira secundária, ou seja, sempre associada ao uso de outra estratégia. Classificamos essa estratégia como uso de datilologia: é a estratégia em que os TILSP fizeram uso do alfabeto manual, ou alfabeto datilológico para soletrar algum nome que não tenha sinal, ou para "traduzir" algum termo cujo sinal era desconhecido.

Tivemos em nosso corpus - não como estratégia de interpretação das UFs, mas como apoio às estratégias principais utilizadas nas interpretaçôes dessas expressões - a utilização da estratégia uso de pergunta retórica, apresentada na classificação de Hortêncio (2005). Por essa estratégia, consideramos as vezes em que o tradutor-intérprete "faz uma pergunta" ao seu interlocutor para, geralmente, em seguida, interpretar o que foi dito. Essa estratégia veio em acompanhamento a outras estratégias de interpretação que foram efetivamente as estratégias de interpretação das UFs. A estratégia do uso de pergunta retórica funcionou, em algumas situações, como uma "introdução" à interpretação da unidade fraseológica.

Entendemos que a estratégia uso de datilologia e a estratégia uso de pergunta retórica funcionaram nas situações de interpretações, das unidades fraseológicas, como estratégias de apoio ou satélites, ou seja, são estratégias que estão sempre "em torno", à disposição de uma interpretação, para que o tradutor-intérprete possa utilizá-las quando necessário. Essas estratégias satélites, principalmente o uso de pergunta retórica, parecem, muitas vezes, funcionar como uma estratégia a mais, que dá ao tradutor-intérprete um "tempo extra" na interpretação, para que ele possa pensar a melhor forma de interpretar uma informação que ainda será dada, mas que não tem "equivalentes" diretos na língua alvo ou que não está posta de maneira 
transparente na língua fonte e precisaria de elementos adicionais para recuperar a informação dada. Então, diante do uso dessas estratégias que a princípio "não traduzem nada", nós temos, na verdade, estratégias que ajudarão o TILSP a recuperar, geralmente através da explicação, uma informação dada pelo interlocutor do discurso.

Fazemos, a seguir, uma breve análise - de algumas das UFs apresentadas na tabela acima - das estratégias de interpretação identificadas no processo de interpretação das unidades fraseológicas no discurso de políticos da ALEC.

Nas UFs abaixo, temos o uso da estratégia da tradução literal. Por essa estratégia, consideramos as interpretaçôes que mantiveram uma 'fidelidade' semântica à língua fonte, mas se adequaram à forma (estrutura) na língua de chegada.

Nas duas sentenças a seguir, temos realizações (variações) de uma mesma unidade fraseológica "PROBLEMA GRAVE".

\section{Deputado: PROBLEMA GRAVÍSSIMO \\ TILSP: PROBLEMA+ SÉRIO \\ Deputado: GRAVE PROBLEMA que estamos vivenciando TILSP: PROBLEMA+ <exp. f ...int..> TER AGORA}

Nas duas variações tivemos a interpretação do TILSP S3 e pudemos constatar, na observância das ocorrências, que ele se utilizou de estratégias diferenciadas na hora de interpretar cada uma das variações. Na primeira ocorrência, "PROBLEMA GRAVÍSSIMO" ele utilizou apenas a estratégia da tradução literal, utilizando os sinais de "PROBLEMA" e "SÉRIO"; já na segunda ocorrência, utilizou - além da tradução literal - a estratégia do apagamento, ele fez o apagamento do sinal "SÉRIO"; mas, em substituição ao sinal apagado, o TILSP fez o uso de uma expressão facial de intensidade para denotar e deixar claro o grau de gravidade do problema, e que não se tratava apenas de um simples problema. Ao utilizar essa expressão, o tradutor-intérprete recorreu a um recurso próprio da língua de sinais, não chegando a ser essa utilização um uso específico de uma estratégia, pois o próprio termo "GRAVE" já demandaria, em uma interpretação em Língua de Sinais, o uso de uma expressão facial que traduzisse a intensidade de sentido do termo.

Vejamos o próximo exemplo, no qual o TILSP utiliza a estratégia da simplificação: 
Deputado: EM VERDADE EM VERDADE VOS DIGO nobre e divinal figura (...)

\section{TILSP: AGORA VERDADE AVISAR}

Sabemos que na estratégia de simplificação o tradutor/intérprete reduz ou simplifica a informação dada para uma melhor compreensão do conteúdo, por parte de quem recebe a tradução/interpretação na língua alvo.

Percebemos na glosa de interpretação acima que o TILSP não somente reduziu a informação como também 'quebrou' o grau de rebuscamento e formalidade que é exigido dessa unidade fraseológica. Nesse caso, o TILSP adaptou a UF, que enquanto citação nos remete imediatamente à fala de Jesus Cristo, para um enunciado que parece ser claro e direto. Diante dessa tomada de decisão do TILSP, acreditamos em duas possibilidades: 1) o TILSP acredita que é difícil interpretar essa citação remetendo à sua origem, e com isso usa a estratégia da simplificação sem maiores rodeios (consciente ou inconscientemente); 2) o TILSP não recupera em seu conhecimento linguístico, cultural, social e religioso a origem da expressão utilizada pelo deputado, sendo essa, acreditamos, uma possibilidade mais remota.

Levando em consideração o pouco tempo disponível que o tradutor/ intérprete tem no momento de uma interpretação simultânea, acreditamos que o TILSP já teria que ter à mão outras estratégias para que fosse possível 'recuperar' a UF da língua fonte na língua alvo, recuperando a sua característica de citação.

Classificamos por apagamento ou omissão todas as vezes que identificamos na interpretação dos TILSP a utilização da estratégia de apagar total ou parcialmente as unidades fraseológicas identificadas nos pronunciamentos dos políticos, como vemos a seguir:

Deputado: DANÇOU E BAILOU no palco

TILSP: $\Phi$ <omissão>

Vemos na glosa acima que o TILSP apagou completamente a colocação "DANÇOU E BAILOU”. Consideramos a hipótese de que, ao realizar o apagamento de alguma sentença ou alguma parte do discurso, o profissional tradutor-intérprete acredite que está tirando do texto informaçōes que não são relevantes ou que são repetitivas. 
Em nossa entrevista aos TILSP percebemos essa assertiva nos discursos de alguns deles. Alguns defendem que utilizar a estratégia da omissão em alguns momentos é importante para uma melhor organização do discurso. Um sujeito de pesquisa afirma: "Eu também uso uma estratégia de subtração, quando eu acho que é necessária." (TILSP S5). Isso porque, para esse sujeito, em nossas falas "nós, ouvintes, temos o hábito de enxertar, enxertamos palavras ou expressões que não têm significado nenhum." (TILSP S5). Pela fala desse tradutor-intérprete, a utilização da estratégia da omissão parece ser uma decisão consciente, parece ser uma necessidade a partir de algum ponto motivador, seja por achar que a informação não é relevante, seja por uma questão de economia de tempo, seja por não saber como fazer a interpretação.

No exemplo abaixo temos o uso da expressão idiomática "TAPAR O SOL COM A PENEIRA", fazendo referência a uma decisão política. Observamos, ao assistir aos vídeos, que o tradutor-intérprete ao fazer a interpretação dessa expressão se utilizou da estratégia que chamamos de paráfrase descritiva. Nessa estratégia, os TILSP devem buscar, na própria Língua de Sinais, os recursos disponíveis para ajudar na interpretação entre as duas línguas. Vejamos:

\section{Deputado: querer TAPAR O SOL COM UMA PENEIRA TILSP: PARECE+ SOL(md) CL: 5 PARAR(me) <exp. f. neg> CL: 5 ULTRAPASSAR(md)}

O intérprete fez uso do espaço de sinalização e de classificadores. Primeiramente, localizou o sol acima de sua cabeça; depois utilizou o espaço à frente e um pouco acima de seu corpo e, com a palma da mão aberta, como em um movimento de PARE, localizou a "PENEIRA"; mantendo esse ponto de referência, um classificador para a peneira, simulou os raios do sol que ultrapassavam essa "peneira". Simultaneamente a isso, ele se utilizou de um movimento e de uma expressão facial de intensidade para ratificar que não adiantava querer escamotear uma situação que era clara, caracterizando assim, a situação de "TAPAR O SOL COM A PENEIRA".

Para a realização da estratégia da paráfrase descritiva, os TILSP exploraram o espaço de sinalização e fizeram uso, principalmente, de classificadores. Os classificadores em Língua de Sinais são formados, 
basicamente, por Configurações de Mãos (CMs). ${ }^{11}$ Os classificadores são morfemas afixados a um item lexical; nas Línguas de Sinais, geralmente, esses morfemas se ligam "aos verbos de movimento ou de localização, indicando o objeto que se move ou é localizado" (FERREIRA-BRITO, 1995, p. 103), ou seja, para a sua realização, os classificadores se incorporam ao movimento e/ou localização de um verbo.

Em outro exemplo, "TRANSITAMOS E ANDAMOS”, o TILSP trabalha com os classificadores (CL) "G1" e "V" para ilustrar a situação em que pessoas caminham de um lado a outro. Vemos o CL "G1" incorporado aos verbos "IR-VIR", e o CL "V" incorporado ao verbo "ANDAR", ambos os classificadores designativos do sinal de "PESSOA".

De acordo com Ferreira-Brito (1995), além das CMs, os classificadores também podem ser constituídos por outro elemento, a orientação da mão, ${ }^{12}$ que pode ser um componente diferenciador em certos classificadores, como por exemplo, o CL "V". Vejamos as figuras abaixo:

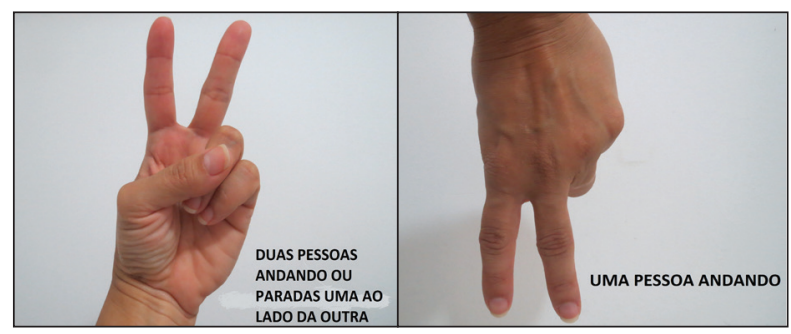

FIGURA 2: Configuração de mão "V"

Dessa forma, temos classificadores constituídos por CMs e outros constituídos por CMs e por orientação da mão.

Utilizando essa estratégia, o TILSP buscou na Língua de Sinais, através de recursos visuais e espaciais da língua, aproximar o significado entre as expressões nas duas línguas. Como defende Bassnett (2005), no processo de tradução de expressões idiomáticas devemos "substituir" a expressão

\footnotetext{
${ }^{11}$ A configuração de mãos está relacionada às diversas formas que a(s) mão(s) toma(m) na realização dos sinais.

${ }^{12}$ Lembrando que a orientação da(s) mão(s) é a direção da palma da mão durante a realização do sinal, que pode ser voltada para baixo, para cima, para o corpo, para frente, para a esquerda ou para a direita.
} 
idiomática (EI) da língua fonte por outra EI na língua meta. Embora nós saibamos que esse não é um processo simples, e nem linear - toda tradução/ interpretação é uma ressignificação de conteúdos, tendo em vista que o tradutor/intérprete não é uma "peça" neutra nesse processo, não é apenas um repassador -, podemos concluir que os tradutores/intérpretes, ao fazerem uma tradução, tentam "aproximar" a língua-alvo da língua-fonte.

No exemplo a seguir, temos uma situação de interpretação na qual o tradutor-intérprete utiliza três estratégias de interpretação: a explicitação, a datilologia e a paráfrase explicativa.

Deputado: hoje certamente é DIA DE LUTO para (...)

TILSP: HOJE É NÓS-todos TRISTE(md)(me) L-U-T-O IGUAL PRETO NÓS LEMBRAR

Para a interpretação de 'DIA DE LUTO', percebemos na sinalização do TILSP três momentos distintos, cada um deles marcado por uma estratégia de interpretação: primeiro, ele diz que todos estão tristes, informação não dada pelo deputado que realiza o discurso, ou seja, o TILSP acrescentou essa informação ao texto, utilizando-se da explicitação; segundo, o tradutor-intérprete utiliza o alfabeto manual para escrever a palavra L-UT-O, estratégia considerada por nós e classificada como uso de recursos visuais; e terceiro, o TILSP faz uso da paráfrase explicativa para dar uma 'explicação' do que seria um dia de luto: para isso, ele faz o sinal IGUAL e logo em seguida explica a expressão, fazendo referência à roupa preta que usamos em sinal de respeito ao momento de tristeza.

Essa decisão tradutória do TILSP em utilizar, além da estratégia da explicitação e da datilologia, a estratégia da paráfrase explicativa, nos parece ser consciente, pois, de acordo com esse mesmo tradutor-intérprete (em entrevista realizada) se há "uma informação que eu acho que a datilologia não dá conta [...]. Então, se eu utilizar da datilologia, eu tenho que fazer uma paráfrase." (TILSP S6). Mas constatamos em nosso trabalho que nem todas as vezes que tivemos o uso da datilologia pelos TILSP, enquanto estratégia, esta veio acompanhada de uma paráfrase explicativa.

$\mathrm{Na}$ interpretação do TILSP acima, na qual identificamos três estratégias, podemos também evidenciar, além do papel de mediador cultural do tradutor-intérprete e de toda a sua visibilidade na tradução, a sua condição de "agente do discurso", pois, enquanto mediador cultural o tradutor- 
intérprete será sempre produtor e responsável pelo enunciado produzido. Dessa maneira, o interlocutor do discurso só terá verdadeiramente acesso à "voz" do tradutor/intérprete, pois o autor do discurso seria apenas uma "imagem" construída através da fala desse tradutor/intérprete.

Venuti (2002) defende a visibilidade do tradutor/intérprete em um processo tradutório. Além disso, o autor também reivindica o papel autoral do tradutor/intérprete em uma tradução, uma vez que o texto/discurso do autor nunca terá uma "originalidade" em sua autoria, pois todo enunciado sempre será uma "reescritura de materiais culturais preexistentes" (VENUTI, 2002, p.99). Dessa forma, a tradução/interpretação também pode ser considerada autoria, partindo do princípio de que o tradutor/intérprete fará escolhas para a reelaboração do texto/discurso traduzido, embora essas escolhas não sejam completamente livres, pois serão determinadas por uma ideologia e limitadas pelas línguas.

Em nosso corpus encontramos muitas realizações de interpretações nas quais os TILSP buscaram a estratégia da paráfrase, mais especificamente da paráfrase explicativa. Mas, em algumas situaçóes, utilizaram essa estratégia de maneira parcial, quando omitiram parte da informação da UF; ou de maneira frustrada, quando a interpretação pela estratégia da paráfrase explicativa não deu conta da tradução da UF; ou quando essa estratégia veio associada a outra estratégia, nessa situação específica, associada à estratégia classificada na literatura como estratégia do uso de pergunta retórica.

No exemplo a seguir, as interpretações não obtiveram, no nosso entendimento, sucesso em relação ao dito em Língua Portuguesa e ao interpretado em Língua de Sinais. A essas ocorrências nós chamamos de paráfrase explicativa frustrada.

Consideramos relacionadas a essa subcategoria as tentativas de interpretação por meio de uma "explicação", mas que nessa busca pela interpretação a intertextualidade da unidade fraseológica não é totalmente recuperada pelo tradutor-intérprete.

\section{Deputado: TOQUE DE RECOLHER ${ }^{13}$ 1) TILSP: HORA 12 PEGAR+}

\footnotetext{
${ }^{13}$ Essa UF foi pronunciada várias vezes durante o mesmo discurso de um deputado, sendo esse deputado aparteado por vários outros deputados. Ou seja, a unidade fraseológica TOQUE DE RECOLHER foi utilizada por mais de um orador, mas interpretada pelo mesmo TILSP.
} 
2) TILSP: CL: 5 (me) CL: $̈$ (md) TOCAR-CAMPAINHA PEGAR+

3) TILSP: PEGAR+ JUNTAR-GRUPO

4) TILSP: PEGAR+ JUNTAR-GRUPO LEVAR

5) TILSP: POLÍCIA FAVELA MANDAR

IGUAL (me) muitas-pessoas IR PRESO CASA

IGUAL (md) muitas-pessoas IR

6) TILSP: CARRO CL: B CARONA-LEVAR CL: " 5

7) TILSP: HORA CARRO CL: B JOGAR-DENTRO CARONALEVAR CL: " 5

8) TILSP: $\phi<$ <omissão>

9) TILSP: HORA POLÍCIA CARRO CL: B JOGAR-DENTRO CARONA-LEVAR CL: "5

10) TILSP: HORA POLÍCIA VIGIAR CARRO CL: B JOGARDENTRO CARONA-LEVAR CL: " 5

Sabemos que o tradutor/intérprete não é um sujeito neutro em um processo tradutório; entendemos também que em consequência disso a tradução-interpretação de textos/discursos será influenciada pelo conhecimento de mundo que o profissional tem e que certamente esse profissional não tem a obrigação de conhecer tudo.

Vimos que em todas as interpretaçôes realizadas pelo TILSP, a intertextualidade da UF "TOQUE DE RECOLHER" não é recuperada. Em todas as glosas de interpretações observamos que o TILSP buscou elementos para a interpretação não na unidade fraseológica, mas em informações adicionais que foram fornecidas pelos políticos em suas falas.

Nas glosas 1, 3 e 4 temos as tentativas de interpretação pela estratégia simples da paráfrase explicativa; já nas glosas 2, 5, 6, 7, 9 e 10 temos as tentativas de interpretação pela estratégia da paráfrase explicativa associada à estratégia da paráfrase descritiva. Sabemos que a estratégia da paráfrase descritiva é marcada, principalmente, pelo uso dos classificadores. E é exatamente a esse recurso que o TILSP recorre para tentar interpretar “TOQUE DE RECOLHER".

Observamos também que o TILSP tentou padronizar a interpretação da UF, como podemos perceber nas glosas de interpretação de números 7, 9 e 10, mesmo que o sentido interpretado não esteja totalmente relacionado ao significado da unidade fraseológica em questão. 
Vejamos no exemplo a seguir uma ocorrência das estratégias 'pergunta retórica + paráfrase explicativa’:

Deputado: isso é consequência do AQUECIMENTO GLOBAL

TILSP: PORQUE <.....> O-QUE+ É POR-CAUSA MUNDO DENTRO PARECER CLIMA QUENTE AUMENTAR

A estratégia da paráfrase explicativa associada à estratégia da pergunta retórica constitui-se, basicamente, em o tradutor-intérprete utilizar-se de uma pergunta para introduzir a interpretação de parte do discurso de um orador, seja para que o TILSP tenha tempo de pensar a melhor forma de interpretar uma informação, seja para destacar ideias importantes, e prender a atenção de quem acompanha o discurso; e/ou para estimular o raciocínio (Cf. HORTÊNCIO, 2005 - grifo nosso). No caso de nossa investigação, essa estratégia apareceu para introduzir a interpretação de uma unidade fraseológica, entendemos que para estimular o raciocínio de quem acompanha o discurso e para o ganho de tempo do TILSP enquanto pensava a melhor forma de interpretação. A estratégia do uso de pergunta retórica não foi utilizada como estratégia de interpretação da unidade fraseológica. O uso dessa estratégia foi marcado, principalmente, pelo acompanhamento da estratégia da paráfrase explicativa.

Como podemos observar, na ocorrência acima, vemos que a sentença interpretada é precedida pelas perguntas 'O-QUE e PORQUE', e logo em seguida temos a 'explicação' da unidade fraseológica dada pelo TILSP através de uma paráfrase, que denominamos de explicativa, justamente porque nos parece que o TILSP busca - não somente na UF, mas no conjunto de informaçóes que o discurso do parlamentar traz e em seu conhecimento de mundo - elementos textuais e extratextuais para interpretar a UF.

\section{CONCLUSÃO}

Chegamos ao final de nossa discussão e apresentamos, nestas considerações finais, os principais resultados por nós encontrados nesta pesquisa. Não queremos dizer com isso que consideramos que esta discussão esteja encerrada. Muito pelo contrário, consideramos que ela é apenas o início de investigações futuras que envolvam áreas de pesquisa tão extensas, ricas em informações e ainda pouco investigadas, como são os Estudos da 
Tradução e da Fraseologia em Língua de Sinais. Nenhuma pesquisa se encerra em si, mas é o ponto de partida para outras investigaçōes. Em nossos estudos trazemos apenas a ponta de um iceberg que ainda tem muito a ser explorado.

Inicialmente, tínhamos a hipótese de que as situações interpretativas entre essas duas línguas (Português e Libras), nas quais tivéssemos interpretações de unidades fraseológicas, demandaria sempre do profissional tradutor-intérprete uma busca pelo sentido/significado das UFs realizadas em Língua Portuguesa, ou seja, sempre teríamos a realização de paráfrases, fazendo com que, assim, não recuperássemos a noção de unidade fraseológica em Língua de Sinais, o que em parte se confirmou. Mas percebemos em nossa análise que em muitas situações de interpretação dessas UFs os TILSP buscaram outras alternativas de interpretação que não somente a paráfrase.

A essas "alternativas" de interpretação nós denominamos de estratégias. A análise do corpus da pesquisa aponta o uso principal de seis estratégias, são elas: simplificação, explicitação, tradução literal, paráfrase, equivalência e apagamento ou omissão. No entanto apareceram outras duas estratégias que foram utilizadas de maneira mais secundária, aparecendo sempre associadas a outras estratégias. Nós chamamos essas estratégias secundárias de estratégia satélite. Uma delas foi a estratégia da datilologia; a outra foi a estratégia da pergunta retórica, que não surgiu como estratégia de interpretação da UF, mas como apoio a essa interpretação. $\mathrm{Na}$ maioria das vezes, a estratégia da pergunta retórica veio em acompanhamento à estratégia da paráfrase explicativa. Entre as seis estratégias por nós classificadas, percebemos que duas foram mais utilizadas: a paráfrase e a omissão. A paráfrase foi a estratégia que teve maior número de ocorrências e aconteceu em duas manifestações: o da paráfrase explicativa e o da paráfrase descritiva.

Os dados apresentados neste estudo nos apontam a necessidade de mais pesquisas acerca da prática tradutória do profissional tradutorintérprete de Língua de Sinais, estudos que possam auxiliá-lo na sua prática profissional. Percebemos isso, principalmente, no que concerne ao nosso foco de pesquisa que são as estratégias utilizadas pelos TILSP para a interpretação de unidades fraseológicas. Entendemos que novos estudos possam, por exemplo, direcionar a criação de dicionários, manuais, apêndices que tragam ao conhecimento do profissional da tradução unidades fraseológicas nas duas línguas, a Língua Portuguesa e a Língua Brasileira de Sinais, se constituindo em ferramentas que certamente os auxiliariam no processo tradutório. 


\section{REFERÊNCIAS}

ALMEIDA, M. J. D. F. de. A Tradução e interpretação de provérbios e expressóes idiomáticas em Lingua de Sinais: equivalentes linguísticos e culturais. 2010. Disponível em: <http://www.congressotils.cce.ufsc.br/2010/pdf/maria_jose_ duarte_freire_de_almeida.pdf >. Acesso em: 19 dez. 2011.

ALVES, F; MAGALHĀES, C.; PAGANO, A. Traduzir com autonomia: estratégias para o tradutor em formação. 3. ed. São Paulo: Contexto, 2006.

BASSNETT, Susan. Estudos da tradução. Porto Alegre: Editora da UFRGS, 2005. BARBOSA, H. G. Procedimentos técnicos da tradução: uma nova proposta. 2.ed. Campinas, SP: Pontes, 2004.

CORPAS PASTOR, G. C. Manual de fraseologia española. Madrid: Gredos, 1996.

FARIA, S. P. A metáfora na LSB e a construção dos sentidos no desenvolvimento da competência comunicativa de alunos surdos. 2003. 316f. Dissertação (Mestrado em Linguística) - Universidade de Brasília, Brasília, 2003.

FELIPE, T. A. Introdução à gramática da LIBRAS. In: Educação Especial-Língua Brasileira de Sinais, série deficiência auditiva, vol.3, fascículo 7, Brasília: MEC/ SEESP, 1997.

FERREIRA-BRITO, L. Por uma gramática de Língua de Sinais. Rio de Janeiro: Tempo Brasileiro, 1995.

GILE, D. Methodological Aspects of Interpretation (and Translation) Research. Target, v.3, n.2. Philadelphia: Benjamins, p.153-174, 1991.

GURILLO, L. R. Aspectos de fraseología española. Valencia: Universidad de Valencia, 1997.

HORTÊNCIO, G. F. H. Um estudo descritivo sobre o papel dos intérpretes de LIBRAS no âmbito organizacional das Testemunhas de Jeová. 2005. 108f. Dissertação (Mestrado em Linguística Aplicada) - Universidade Estadual do Ceará, Fortaleza. JORGE, G. Da palavra às palavras: alguns elementos para a tradução das expressões idiomáticas. Polifonia, Lisboa: Edições Colibri, n.5, p.119-133, 2002.

LEMOS, A. M. As estratégias de interpretação de unidades fraseológicas do Português para a Libras em discursos de políticos. 2012. 177f. Dissertação (Mestrado em Linguística) - Universidade Federal do Ceará, Fortaleza, 2012.

LIDDELL, S. K.; JOHNSON, R. E. American Sign Language: the phonological base. In: VALLI, C.; LUCAS, C. (Org.). Linguistics of American Sign Language: an introduction. Washington-DC: Clerc Books/Gallaudet University press, 2000.

MITTMANN, S. Notas do tradutor e processo tradutório: análise e reflexão sob uma perspectiva discursiva. Porto Alegre: Editora UFRGS, 2003. 
NOVAIS, L. O intérprete de tribunal, um mero intérprete?: um estudo descritivo sobre o papel do intérprete nos Fóruns de Boa Vista, RR e Fortaleza, CE. 2002. 397p. Dissertação (Mestrado em Linguística Aplicada) - Centro de Humanidades da Universidade Estadual do Ceará, Fortaleza.

PAGURA, R. A interpretação de conferências: interfaces com a tradução escrita e implicaçōes para a formação de intérpretes e tradutores. DELTA [online]. vol.19, n.spe, p. 209-236. 2003.

QUADROS, R. M. de; PIZZIO, A. L. Lingua brasileira de sinais IV. Curso de Letras Libras. CCE/UFSC - 2009.

SAUSSURE, F. de. Curso de linguística geral. Organizado por Charles Bally, Albert Sechehave; colaboração de Albert Riedlinger. Tradução: Antônio Chelini, José Paulo Paes e Izidoro Blikstein. 27ª.ed. São Paulo: Cultrix, 2006.

STROBEL, K. As imagens do outro sobre a cultura surda. Florianópolis: Ed. da UFSC, 2008.

STUMPF, M. R. Transcrições de Língua de Sinais Brasileira em signwriting. In: LODI, A. C. B.et al (Org.). Letramento e minoria. 2.ed. Porto Alegre: Editora Mediação, 2003.

TAGNIN, S. E. O. O jeito que a gente diz: expressões convencionais e idiomáticas. São Paulo: Disal, 2005.

TOURY, G. The Nature and Role of Norms in Translations. In: Descriptive Translation Studies and Beyond. Amsterdam-Philadelphia: John Benjamins, 1995. p.53-69.

VENUTI, L. Escândalos da tradução: por uma ética da diferença. Bauru-SP: EDUSC, 2002.

XATARA, C.; RIVA, H. C.; RIOS, T. H. As dificuldades na tradução de idiomatismos. Cadernos de Tradução, Florianópolis: UFSC, v.2, n.8, p.183-194, 2001. Disponível em: <http://www.periodicos.ufsc.br/index.php/traducao/article/ viewFile/5892/5572>. Acesso em: 7 abr. 2010.

ZULUAGA, A. Introducción al estudio de las expresiones fijas. Bern, 1980.

Data de submissão: 28/02/2014. Data de aprovação: 27/06/2014. 